\title{
DURABILIDADE DE SOLOS ESTABILIZADOS QUIMICAMENTE COM VISTAS À APLICAÇÃO EM ESTRADAS FLORESTAIS ${ }^{1}$
}

\author{
Carlos Cardoso Machado², Giovani Levi Sant’Anna ${ }^{3}$, Dario Cardoso de Lima ${ }^{4}$, Carlos Alexandre Braz de \\ Carvalho $^{4}$, Antônio Almeida ${ }^{5}$ e Tales Oliveira ${ }^{5}$
}

\begin{abstract}
RESUMO - Este artigo é direcionado à caracterização do parâmetro durabilidade de dois solos típicos da microrregião de Viçosa, Minas Gerais, para fins de aplicação em estradas florestais, considerando-se, para tanto, as seguintes condições: (a) solos estabilizados com o resíduo industrial "grits"; (b) solos melhorados com cal ou cimento; e (c) solos estabilizados com grits e melhorados com cal ou cimento, a partir de resultados de ensaios de durabilidade por molhagem e secagem. Trabalhou-se com um solo residual maduro (solo 1) e um solo residual jovem de gnaisse (solo 2) da Zona da Mata Norte de Minas Gerais, Brasil. O programa de ensaios de laboratório envolveu: (a) teor de grits: $24 \%$ calculado em relação ao peso de solo seco; (b) teor de cal ou cimento: 10 e $20 \%$, calculados em relação ao peso de grits seco; (c) energias de compactação: referentes aos ensaios Proctor normal e modificado; e (d) período de cura: sete dias em câmara úmida. Os resultados do programa de ensaios indicaram que: (a) as misturas solo-cal, solo-cimento, solo-grits-cal e solo-grits-cimento, em ambas as energias empregadas, resistiram a todos os ciclos do ensaio de durabilidade por molhagem e secagem; (b) a mistura solo $1+$ grits + cal apresentou o melhor resultado, quando compactada na energia modificada, com perdas da ordem de 7\%; com relação ao solo 2, o melhor resultado foi obtido quando se trabalhou com grits mais cimento, na energia modificada, com perdas da ordem de 9\%; e (c) sob o aspecto durabilidade, as misturas solo-grits só apresentam potencial para emprego como material de construção rodoviária quando melhoradas com cal ou cimento.
\end{abstract}

Palavras-chave: Estabilização de solos, resíduo industrial "grits”, estradas florestais e durabilidade.

\section{DURABILITY OF CHEMICALLY STABILIZED SOILS FOR FOREST ROAD APPLICATIONS}

\begin{abstract}
This paper addresses the assessment of the durability properties of mixtures of two soils using laboratory wetting and drying durability tests for forest road applications, as follows: (a) soils stabilization with the industrial waste grits; (b) soil improvement using lime or cement; (c) soil stabilization using grits, and soil mixture improvement using lime or cement. A mature and a young residual soil from the Zona da Mata Norte of Minas Gerais were used throughout the study. The laboratory testing program comprised the following steps: (a) grits content of $24 \%$ in relation to soil dry mass; (ii) lime or cement contents of $10 \%$ and $20 \%$ in relation to grits dry mass; (c) specimens compacted at the standard and modified Proctor effort; (d) mixture specimens curing time of seven days in acclimatized room. The testing program data supported
\end{abstract}

\footnotetext{
${ }^{1}$ Recebido em 24.02.06 e aceito para publicação em 03.10.2006.

${ }^{2}$ Departamento de Engenharia Florestal da Universidade Federal de Viçosa, 36570-000 Viçosa-MG. E-mail: <machado@ufv.br>.

${ }^{3}$ Programa de Pós-Graduação em Ciência Florestal da Universidade Federal de Viçosa.

${ }^{4}$ Departamento de Engenharia Civil da Universidade Federal de Viçosa.

${ }^{5}$ Graduação do Departamento de Engenharia Civil da UFV.
} 


\begin{abstract}
that: (a) the soil-lime, soil-cement, soil-grits-lime and soil-grits-cement mixtures endured all cycles in the durability test; (b) the mixtures of soil 1, grits and lime compacted at the modified Proctor effort presented the best mechanical response in the durability tests, showing losses of approximately $7 \%$; regarding soil 2 mixtures, the best result was related to the grits and cement mixtures compacted at the modified Proctor effort, showing losses of approximately $9 \%$; (c) as for durability standard requirements, the mixtures of soilgrits presented potential for road engineering applications only in association with lime or cement.
\end{abstract}

Keywords: Soil stabilization, industrial waste grits, forest roads and durability tests.

\section{INTRODUÇÃO}

A busca por material alternativo para uso na construção de pavimentos rodoviários justifica-se pelo fato de que o setor rodoviário é responsável por mais de $70 \%$ das cargas transportadas no Brasil, bem como pela extensão das estradas públicas vicinais. Associase a esse fato a necessidade de que as rodovias sejam trafegáveis durante todo o ano com qualidade e maior segurança, diminuindo, assim, o número excessivo de acidentes nas estradas, danos à frota nacional de veículos e ao meio ambiente.

Essas constatações abrem um campo amplo para a busca de material alternativo, de baixo custo e elevado desempenho técnico, para a construção de pavimentos rodoviários, garantindo resistência mecânica e vida útil adequadas. Assim, além de contribuir para solucionar a problemática da pavimentação em muitas regiões brasileiras, podese viabilizar a retirada de resíduos industriais muito vezes poluentes do meio ambiente, através dos seus empregos na estrutura de rodovias.

Sob esse prisma, uma solução tecnológica que vem apresentando resultados satisfatórios, do ponto de vista de resistência mecânica, é a aplicação do resíduo sólido industrial grits como aditivo químico para melhorar as características geotécnicas dos solos. Contudo, maiores estudos são necessários para a caracterização tecnológica das misturas solo-grits, com a abordagem do aspecto durabilidade. Esse foi o objetivo deste artigo, considerando-se o parâmetro durabilidade para fins de aplicação em estradas florestais.

Segundo Lima et al. (1993), a durabilidade pode ser definida como sendo a capacidade de um material manter a sua integridade quando submetido à ação de agentes externos. Entre as formas de avaliação da durabilidade está a perda de peso ou a variação de absorção ou expansão no final de determinado tempo ou número de ciclos de uma ação periódica, a exemplo da secagem e molhagem, como destacou Pereira (2005).

A literatura técnica é rica em relatos sobre o estudo da durabilidade por molhagem e secagem de misturas solo-cimento. Contudo, com relação a outros estabilizantes químicos, não se tem muita informação sobre estudos prévios, em especial sobre aqueles dirigidos à durabilidade das misturas solo-resíduos. Trabalhos sobre durabilidade relativos ao emprego de outros estabilizantes químicos como o RBI Grade 81 (TRINDADE et al., 2005) e a escória de alto-forno granulada (SANT'ANA, 2003) desenvolvidos com solos da Zona da Mata Norte de Minas Gerais, embora escassos, trazem informações de interesse sobre o parâmetro durabilidade de solos estabilizados quimicamente.

Trabalhando com um solo residual maduro, classificado pedologicamente como Latossolo VermelhoAmarelo e geotecnicamente como A-7-5 (20), e com dois solos residuais jovens, classificados geotecnicamente como A-6 (1) e A-2-4 (0), estabilizados com $6 \%$ de RBI Grade 81, para corpos-de-prova de misturas compactadas nas energias dos ensaios Proctor normal, intermediário e modificado e curadas durante sete dias em câmara úmida, Trindade et al. (2005) concluíram que, sob o aspecto durabilidade, elas apresentavam bom potencial para emprego como material de construção rodoviária. Empregando o mesmo Latossolo Vermelho-Amarelo e um dos solos residuais jovens (solo A-2-4 (0)) analisados por Trindade et al. (2005), mas estabilizados com os teores 5, 10 e $15 \%$ de uma escória de alto-forno granulada moída ativada com cal hidratada, para corpos-de-prova compactados na energia do ensaio Proctor intermediário e curados por sete dias em câmara úmida, Sant' ana (2003) também concluiu sobre o bom desempenho das misturas para fins rodoviários, sob o aspecto de durabilidade. 


\section{MATERIAL E MÉTODOS}

\subsection{Identificação do Material}

\subsubsection{Solos}

Empregou-se um solo laterítico de grande ocorrência no relevo da cidade de Viçosa, localizada na Zona da Mata Norte de Minas Gerais, Brasil. Esse solo, denominado solo 1, é um Latossolo Vermelho-Amarelo, que se constitui no subleito de rodovias e terreno de fundação de construções civis, localiza-se nos topos de elevações com relevo plano, apresenta expressivo horizonte B profundo, poroso e bem drenado, com granulometria argilo-areno-siltosa (60\% de argila, 22\% de areia e $18 \%$ de silte). Quanto à sua identificação, segundo o sistema rodoviário americano Transportation Research Board (TRB), trata-se de um solo do grupo A-7-5 (16).

Foi utilizado, também, um solo saprolítico de grande ocorrência no relevo do Município de Viçosa. Esse solo, denominado solo 2, de textura arenosa, compõe o manto saprolítico, horizonte C, dos solos da região. Apresenta, ainda, coloração acinzentada, com granulometria arenosilto-argilosa (74\% de areia, $16 \%$ de silte e $10 \%$ de argila). Quanto à sua classificação, segundo o sistema TRB, é um solo do grupo A-2-4 (0).

\subsubsection{Resíduo industrial}

O grits foi cedido pela empresa Cenibra S.A. (Celulose Nipo-Brasileira), situada na região de Ipatinga, Minas Gerais, Brasil. Trata-se de um resíduo sólido industrial, de coloração acinzentada e granulometria diversificada. Foi utilizado no teor de $24 \%$ em relação ao peso de solo seco, com base em estudos desenvolvidos por Pereira (2005).

Esse resíduo, de acordo com a caracterização química efetuada por Pereira (2005), apresenta em sua composição química, cerca de $20 \%$ de cálcio, dos quais $42 \%$ se encontram na forma de óxido de cálcio $(\mathrm{CaO})$, que é um componente de significativo interesse para o sucesso dos processos de estabilização de solos.

\subsubsection{Cal e Cimento}

No presente trabalho, utilizou-se uma cal hidratada comercial empregada em argamassas e denominada, comercialmente, Supercal, bem como um cimento comercial do tipo Portland CP-II E-32. Ao trabalhar com as amostras de solos estabilizadas com grits e melhoradas com cal ou cimento, utilizaram-se esses estabilizantes nos teores de 10 e $20 \%$ em relação ao peso de grits seco. Assim, ao trabalhar com as misturas solo-cal e solo-cimento, na busca de garantir o emprego dos mesmos teores de estabilizantes do caso anterior, utilizaram-se os teores de aditivo de 2,4 e 4,8\% em relação aos pesos de matéria seca dos solos.

\subsection{Ensaios de Laboratório}

\subsubsection{Misturas}

\subsubsection{Solo-resíduo}

As misturas solo-resíduo foram processadas adicionando-se, primeiramente, o resíduo grits ao solo, seguido por homogeneização manual e processamento na peneira de abertura nominal de 4,8 mm. Posteriormente, adicionou-se água em quantitativos definidos previamente, para atingir os parâmetros ótimos de compactação $\mathrm{W}_{\text {ot }}$ (teor ótimo de umidade) e o respectivo $\mathrm{Y}_{\text {dmáx }}$ (peso específico seco máximo), procedendo-se a uma nova homogeneização, peneiramento e acondicionamento das misturas em sacos plásticos hermeticamente fechados, para posterior uso. As misturas solo-grits foram compactadas duas horas após a sua obtenção.

\subsubsection{Solo melhorado com cal ou cimento}

Estas misturas foram realizadas adicionando-se, primeiramente, a cal ou cimento ao solo, seguido por homogeneização manual e peneiramento (\# 4,8 mm). Posteriormente, adicionou-se água em quantitativos definidos previamente, para atingir os parâmetros ótimos de compactação $\left(\mathrm{W}_{\text {ot }}\right.$ e $\left.\mathrm{Y}_{\text {dmáx }}\right)$, procedendo-se a uma nova homogeneização, peneiramento e acondicionamento das misturas em sacos plásticos hermeticamente fechados, para posterior uso.

Levando-se em consideração as reações químicas decorrentes do uso do cimento, reações de hidratação e da cal, reações de trocas catiônicas, as misturas solocimento foram compactadas imediatamente e as misturas solo-cal, duas horas após os respectivos processamentos.

\subsubsection{Solo-resíduo melhorado com cal ou cimento}

Às misturas solo-grits-cal e solo-grits-cimento, adicionou-se, primeiramente, o resíduo grits ao solo,

R. Árvore, Viçosa-MG, v.30, n.6, p.981-988, 2006 
seguido por homogeneização manual e peneiramento (\# 4,8 mm). Em seguida, adicionou-se a cal, ou o cimento, homogeneizou-se novamente e, posteriormente, acrescentou-se água em quantitativos definidos previamente, para atingir os parâmetros ótimos de compactação $\left(\mathrm{W}_{\text {ót }}\right.$ e $\left.\mathrm{Y}_{\text {dmáx }}\right)$, procedendo-se a uma nova homogeneização, peneiramento e acondicionamento dessas misturas em sacos plásticos hermeticamente fechados, para posterior uso.

\subsubsection{Ensaios de Compactação}

Estes ensaios foram realizados visando à obtenção dos parâmetros ótimos de compactação $\left(\mathrm{W}_{\text {ót }}\right.$ e $\left.\mathrm{Y}_{\text {dmáx }}\right)$ das misturas solo-grits, solo-grits-cal e solo-gritscimento, com base na DNER 129/94 (solos compactação utilizando amostras não-trabalhadas), nas energias dos ensaios American Association of State Highways Officials (AASHTO) normal e modificado. Os corpos-de-prova foram compactados por processo dinâmico, utilizando-se o molde do ensaio Proctor, ou seja, um molde cilíndrico de $10,00 \mathrm{~cm}$ de diâmetro interno e $12,73 \mathrm{~cm}$ de altura.

\subsubsection{Ensaio de Durabilidade}

Os ensaios de durabilidade por molhagem e secagem foram executados em conformidade com a Norma DNERME 203/94, pois não se dispõe, no Brasil, de norma técnica específica para outros tipos de misturas estabilizadas quimicamente. Contudo, no presente caso, empregou-se na compactação dos corpos de prova, além da energia do ensaio Proctor normal, a energia do ensaio Proctor modificado. Os ensaios consistiram na determinação da perda de massa dos corpos-deprova quando submetidos a ciclos de molhagem e secagem.

Os corpos-de-prova foram moldados nos parâmetros ótimos de cada energia de compactação empregada, que foram determinados previamente nos ensaios de compactação. Posteriormente à moldagem, os corposde-prova foram identificados e colocados em sacos plásticos, que foram hermeticamente fechados e identificados para evitar troca de umidade com o ambiente. Os corpos-de-prova permaneceram pelo período de sete dias em cura em uma câmara climatizada com umidade relativa do ar superior a $95 \%$. Após esse período de cura, eles foram colocados na caixa de imersão, permanecendo aí por $5 \mathrm{~h}$. A seguir, foram levados para uma estufa a $70^{\circ} \mathrm{C} \pm 2^{\circ}$, onde foram mantidos durante $42 \mathrm{~h}$. Ao fim desse período, sofreram escovadelas com uma força correspondente à massa de $1,5 \mathrm{~kg}$, em toda a sua área, utilizando-se uma escova de fios metálicos. As operações de molhagem, secagem e escovação foram repetidas durante 12 ciclos. Finalizados esses ciclos, os corpos-de-prova foram colocados na estufa à temperatura de 105 a $110^{\circ} \mathrm{C}$ até a constância de massa, para a determinação de suas massas secas. A partir desses dados coletados, determinou-se a perda de massa dos corpos-de-prova de todas as misturas analisadas.

\section{RESULTADOS E DISCUSSÃO}

\subsection{Resultados dos Ensaios de Compactação}

No Quadro 1, apresentam-se os parâmetros peso específico seco máximo ( $\left.\mathrm{Y}_{\mathrm{dmáx}}\right)$ teor ótimo de umidade $\left(\mathrm{W}_{\text {ot }}\right)$ dos solos e respectivas misturas compactadas nas energias referentes aos ensaios Proctor normal e modificado.

Os resultados apontaram mostraram que o aumento da energia de compactação foi responsável por incrementos nos valores de peso específico aparente seco máximo e reduções nos valores de umidade ótima das misturas. Os maiores valores de peso específico aparente seco máximo relacionam-se ao solo 2 , de característica granular, sendo que o solo 1 , com maior porcentual de argila, apresentou os maiores teores de umidade ótima.

Observa-se, também, que a adição de grits influenciou os parâmetros ótimos de compactação dos solos 1 e 2 , sendo que no primeiro caso o resíduo proporcionou melhoria nas características de compactação, fato comprovado pela redução nos teores ótimos de umidade e aumento nos pesos específicos secos máximos (PEREIRA, 2005). Com relação à adição de cal ou cimento, de modo geral notou-se um comportamento condizente com referências da literatura sobre o tema, observando-se pequenos acréscimos ou decréscimos nos parâmetros ótimos de compactação (FERNANDES, 2000).

\subsection{Resultado dos Ensaios de Durabilidade}

Nos Quadros 2 a 6, apresentam-se os resultados dos ensaios de durabilidade por molhagem e secagem, 
considerando corpos-de-prova dos solos 1 e 2 estabilizados com grits (Quadro 2), corpos-de-prova dos solos 1 e 2 melhorados com cal (Quadro 3) e com cimento (Quadro 4), bem como corpos-de-prova dos solos 1 e 2 estabilizados com grits e melhorados com cal (Quadro 5) e com cimento (Quadro 6), sendo considerados as energias de compactação referentes aos ensaios Proctor normal e Proctor modificado.

Os resultados apresentados nos Quadros 2 a 6 revelam que: (a) as amostras dos solos 1 e 2 melhoradas com cal ou cimento suportaram todos os 12 ciclos do ensaio de durabilidade; (b) as amostras desses solos estabilizadas com o resíduo grits não resistiram ao ensaio de durabilidade, apresentando perda total de massa durante a imersão, ainda no primeiro ciclo do ensaio; (c) as amostras desses solos estabilizadas com o resíduo grits e melhoradas com cal ou cimento resistiram aos 12 ciclos do ensaio de durabilidade por molhagem e secagem. Especificamente, tem-se:
-Solo 1: O solo 1 estabilizado com grits (Quadro 2), em ambas as energias de compactação, não resistiu à imersão do primeiro ciclo, apresentando, assim, uma perda de massa total. Esse solo, quando melhorado com 4,8\% de cal (Quadro 3), na energia modificada, apresentou uma perda de massa da ordem de $14 \%$. Verifica-se, no Quadro 3, que o solo 1 melhorado com $4,8 \%$ de cal, na energia modificada, e o solo 1 melhorado com $2,4 \%$ de cal, na energia normal, apresentaram uma perda de massa da ordem de 31 e $30 \%$, respectivamente. Este solo estabilizado com grits e melhorado com $4,8 \%$ de cal (Quadro 5), compactado na energia modificada, apresentou perda de massa da ordem de 7\%. Comparando os resultados dos ensaios realizados com o solo 1 melhorado com cal (Quadro 3) com aqueles obtidos para o solo 1 estabilizado com o grits e melhorado com cal (Quadro 5), verificou-se que as perdas relativas ao primeiro caso foram significativamente superiores ao segundo, para uma mesma energia e teor de aditivo.

Quadro 1 - Parâmetros dos ensaios de compactação Table 1 -Compaction test parameters

\begin{tabular}{|c|c|c|c|c|}
\hline \multirow[t]{2}{*}{ Material Analisado } & \multicolumn{2}{|c|}{ Energia normal } & \multicolumn{2}{|c|}{ Energia modificada } \\
\hline & $\mathrm{W}_{o \mathrm{t}}(\%)$ & $\mathrm{Y}_{\mathrm{dmaxx}}\left(\mathrm{kN} / \mathrm{m}^{3}\right)$ & $\mathrm{W}_{o t}(\%)$ & $\mathrm{Y}_{\mathrm{dmáx}}\left(\mathrm{kN} / \mathrm{m}^{3}\right)$ \\
\hline \multicolumn{5}{|c|}{ Solo Natural } \\
\hline Solo 1 & 31,80 & 13,80 & 26,49 & 15,37 \\
\hline Solo 2 & 14,00 & 18,10 & 10,00 & 19,01 \\
\hline \multicolumn{5}{|c|}{ SOLO-GRITS } \\
\hline Solo $1+$ grits & 28,90 & 17,90 & 25,85 & 17,10 \\
\hline Solo $2+$ grits & 13,52 & 18,59 & 11,29 & 18,59 \\
\hline \multicolumn{5}{|c|}{ Solo-Cal } \\
\hline Solo 1 + cal (a) & 30,40 & 13,72 & 25,15 & 16,16 \\
\hline Solo 1 + cal (b) & 29,10 & 13,60 & 24,00 & 16,85 \\
\hline Solo 2 + cal (a) & 14,30 & 17,79 & 10,50 & 18,85 \\
\hline Solo $2+\mathrm{cal}(\mathrm{b})$ & 14,50 & 17,20 & 10,60 & 18,83 \\
\hline \multicolumn{5}{|c|}{ Solo-Cimento } \\
\hline Solo $1+$ cimento $(a)$ & 30,80 & 14,30 & 26,85 & 17,05 \\
\hline Solo 1 + cimento (b) & 29,50 & 15,00 & 25,65 & 17,68 \\
\hline Solo 2 + cimento (a) & 14,70 & 18,00 & 11,00 & 18,79 \\
\hline Solo $2+$ cimento (b) & 14,93 & 17,96 & 11,09 & 18,76 \\
\hline \multicolumn{5}{|c|}{ Solo-Grits-Cal } \\
\hline Solo $1+$ grits + cal (a) & 28,90 & 17,92 & 25,10 & 16,23 \\
\hline Solo 1 + grits + cal (b) & 28,86 & 17,94 & 23,96 & 16,87 \\
\hline Solo 2 + grits + cal (a) & 12,86 & 18,71 & 11,70 & 19,25 \\
\hline Solo $2+$ grits + cal (b) & 12,17 & 18,50 & 11,42 & 17,96 \\
\hline \multicolumn{5}{|c|}{ Solo-Grits-Cimento } \\
\hline Solo $1+$ grits + cimento (a) & 30,65 & 14,38 & 26,81 & 17,10 \\
\hline Solo $1+$ grits + cimento $(b)$ & 29,35 & 15,20 & 25,59 & 17,73 \\
\hline Solo $2+$ grits + cimento $(a)$ & 12,71 & 18,59 & 10,53 & 20,02 \\
\hline Solo $2+$ grits + cimento (b) & 12,17 & 19,00 & 8,39 & 19,70 \\
\hline
\end{tabular}




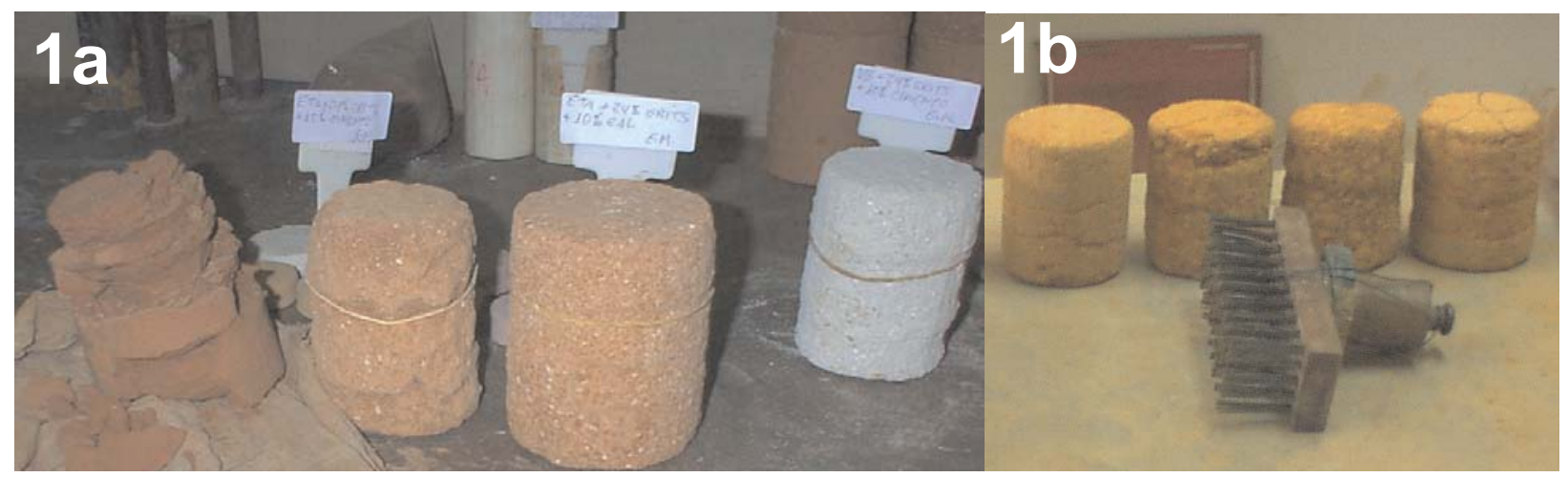

Figura 1 - Corpos-de-prova do ensaio de durabilidade por molhagem e secagem (1a) e escova de aço (1b).

Figure 1 -Specimens of the wetting and drying durability tests (1a) and steel brush (1b).

Quadro 2 - Resultados dos ensaios de durabilidade para as misturas solo $+24 \%$ grits Table 2 - Data from durability tests for soil-grits mixtures

\begin{tabular}{lcccccc}
\hline Mistura & Energia & $\mathrm{mu}(\mathrm{g})$ & $\mathrm{mi}(\mathrm{g})$ & $\mathrm{mf}(\mathrm{g})$ & $\mathrm{mc}(\mathrm{g})$ & Perda de Massa $(\%)$ \\
\hline Solo 1-grits & Normal & 1797,50 & 1394,49 & - & - & 100,00 \\
& Modificada & 1850,30 & 1470,24 & - & - & 100,00 \\
Solo 2-grits & Normal & 1792,80 & 1579,28 & - & - & 100,00 \\
& Modificada & 1967,90 & 1768,26 & - & - & 100,00 \\
\hline
\end{tabular}

Legenda: mu - massa úmida do corpo-de-prova, mi - massa seca inicial; $\mathrm{mf}$ - massa seca final e mc - massa seca final corrigida.

Quadro 3 - Resultados dos ensaios de durabilidade das misturas solo-cal

Table 3 - Data from durability tests for soil-lime mixtures

\begin{tabular}{|c|c|c|c|c|c|c|}
\hline Mistura & Energia & $\mathrm{mu}(\mathrm{g})$ & $\mathrm{mi}(\mathrm{g})$ & $\mathrm{mf}(\mathrm{g})$ & $\mathrm{mc}(\mathrm{g})$ & P. M. $(\%)$ \\
\hline \multirow[t]{2}{*}{ Solo $1+2,4 \%$ cal } & Normal & 1688,65 & 1294,98 & 786,62 & 760,02 & 41,31 \\
\hline & Modificada & 1771,70 & 1415,66 & 1013,93 & 979,64 & 30,80 \\
\hline \multirow[t]{2}{*}{ Solo $1+4,8 \%$ cal } & Normal & 1657,95 & 1284,24 & 928,76 & 897,35 & 30,12 \\
\hline & Modificada & 1785,80 & 1440,16 & 1286,86 & 1243,34 & 13,67 \\
\hline \multirow[t]{2}{*}{ Solo $2+2,4 \%$ cal } & Normal & 1648,50 & 1442,26 & 388,42 & 378,95 & 73,72 \\
\hline & Modificada & 1901,75 & 1721,04 & 1219,91 & 1190,16 & 30,85 \\
\hline \multirow[t]{2}{*}{ Solo $2+4,8 \%$ cal } & Normal & 1673,60 & 1461,66 & 677,08 & 660,56 & 54,81 \\
\hline & Modificada & 1869,60 & 1690,41 & 1421,22 & 1386,56 & 17,97 \\
\hline
\end{tabular}

Legenda: mu - massa úmida do corpo-de-prova, mi - massa seca inicial, mf - massa seca final, mc - massa seca final corrigida e PM - perda de massa.

Quadro 4 - Resultados dos ensaios de durabilidade das misturas solo-cimento

Table 4-Data from durability tests for soil-cement mixtures

\begin{tabular}{|c|c|c|c|c|c|c|}
\hline Mistura & Energia & $\mathrm{mu}(\mathrm{g})$ & $\mathrm{mi}(\mathrm{g})$ & $\mathrm{mf}(\mathrm{g})$ & $\mathrm{mc}(\mathrm{g})$ & $\begin{array}{lll}\text { P. } & \text { M. }(\%)\end{array}$ \\
\hline \multirow[t]{2}{*}{ Solo $1+2,4 \%$ cimento } & Normal & 1692,75 & 1294,15 & 818,66 & 790,97 & 38,88 \\
\hline & Modificada & 1814,00 & 1430,03 & 1265,15 & 1222,37 & 14,52 \\
\hline \multirow[t]{2}{*}{ Solo $1+4,8 \%$ cimento } & Normal & 1665,40 & 1286,02 & 864,91 & 835,66 & 35,02 \\
\hline & Modificada & 1845,75 & 1468,96 & 1389,92 & 1342,92 & 8,58 \\
\hline \multirow[t]{2}{*}{ Solo $2+2,4 \%$ cimento } & Normal & 1510,25 & 1316,69 & 422,56 & 412,25 & 68,69 \\
\hline & Modificada & 1706,25 & 1537,16 & 1115,10 & 1087,90 & 29,23 \\
\hline \multirow[t]{2}{*}{ Solo $2+4,8 \%$ cimento } & Normal & 1706,25 & 1484,60 & 1035,08 & 1009,83 & 31,98 \\
\hline & Modificada & 1959,50 & 1763,88 & 1559,92 & 1521,87 & 13,72 \\
\hline
\end{tabular}

Legenda: mu - massa úmida do corpo-de-prova, mi - massa seca inicial, mf - massa seca final, mc - massa seca final corrigida e PM - perda de massa.

R. Árvore, Viçosa-MG, v.30, n.6, p.981-988, 2006 
Quadro 5 - Resultados dos ensaios de durabilidade das misturas solo-grits-cal Table 5 - Data from durability tests for soil-grits-lime mixtures

\begin{tabular}{ccccccc}
\hline Mistura & Energia & $\mathrm{mu}(\mathrm{g})$ & $\mathrm{mi}(\mathrm{g})$ & $\mathrm{mf}(\mathrm{g})$ & $\mathrm{mc}(\mathrm{g})$ & P. M. $(\%)$ \\
\hline Solo $1+24 \%$ grits + & Normal & 1688,10 & 1309,62 & 1021,40 & 986,86 & 24,64 \\
$10 \% \mathrm{cal}$ & Modificada & 1903,90 & 1521,90 & 1423,00 & 1374,88 & 9,66 \\
Solo $1+24 \%$ grits + & Normal & 1760,00 & 1365,82 & 1175,20 & 1135,46 & 16,87 \\
$20 \% \mathrm{cal}$ & Modificada & 1889,80 & 1524,52 & 1459,70 & 1410,34 & 7,49 \\
Solo $2+24 \%$ grits + & Normal & 1784,90 & 1581,52 & 1052,00 & 1026,34 & 35,10 \\
$10 \% \mathrm{cal}$ & Modificada & 2013,50 & 1802,60 & 1592,00 & 1553,17 & 13,84 \\
Solo $2+24 \%$ grits + & Normal & 1766,70 & 1575,02 & 1157,20 & 1128,98 & 28,32 \\
$20 \% \mathrm{cal}$ & Modificada & 1996,00 & 1791,42 & 1639,80 & 1599,80 & 10,70 \\
\hline
\end{tabular}

Legenda: mu - massa úmida do corpo-de-prova, mi - massa seca inicial, mf - massa seca final, mc - massa seca final corrigida e PM - perda de massa.

Quadro 6 - Resultados dos ensaios de durabilidade para as misturas solo-grits-cimento Table 6 -Data from durability tests for soil-grits-cement mixtures

\begin{tabular}{|c|c|c|c|c|c|c|}
\hline Mistura & Energia & $\mathrm{mu}(\mathrm{g})$ & $\mathrm{mi}(\mathrm{g})$ & $\mathrm{mf}(\mathrm{g})$ & $\mathrm{mc}(\mathrm{g})$ & P. M. $(\%)$ \\
\hline Solo $1+24 \%$ grits + & Normal & 1614,90 & 1236,05 & 902,60 & 872,08 & 29,45 \\
\hline $10 \%$ cimento & Modificada & 1872,60 & 1476,70 & 1374,00 & 1327,54 & 10,10 \\
\hline Solo $1+24 \%$ grits + & Normal & 1798,00 & 1390,03 & 1192,70 & 1152,37 & 17,10 \\
\hline $20 \%$ cimento & Modificada & 1943,30 & 1547,34 & 1467,30 & 1417,68 & 8,38 \\
\hline Solo $2+24 \%$ grits + & Normal & 1803,40 & 1600,03 & 997,30 & 972,98 & 39,19 \\
\hline $10 \%$ cimento & Modificada & 1973,40 & 1785,40 & 1577,10 & 1538,63 & 13,82 \\
\hline Solo $2+24 \%$ grits + & Normal & 1776,20 & 1583,49 & 1021,30 & 996,39 & 37,08 \\
\hline $20 \%$ cimento & Modificada & 1922,30 & 1773,50 & 1645,90 & 1605,76 & 9,46 \\
\hline
\end{tabular}

Legenda: mu - massa úmida do corpo-de-prova, mi - massa seca inicial, mf - massa seca final, mc - massa seca final corrigida e PM - perda de massa.

Comparando os resultados dos ensaios realizados com o solo 1 melhorado com cimento (Quadro 3) com aqueles obtidos para o solo 1 estabilizado com o grits e melhorado com cimento (Quadro 6), verificou-se que as perdas relativas ao primeiro caso foram, de modo geral, significativamente superiores ao segundo, para uma mesma energia e teor de aditivo, confirmando os resultados obtidos com as misturas melhoradas com cal. A exceção ficou por conta do solo 1 melhorado com $4,8 \%$ de cimento, na energia modificada, que apresentou uma perda de massa da ordem de $8 \%$, que, para fins práticos, pode ser considerada idêntica à apresentada por esse mesmo solo quando estabilizado com grits e melhorado com $4,8 \%$ de cimento, na mesma energia de compactação.

-Solo 2: O solo 2 estabilizado com grits (Quadro 2), em ambas as energias de compactação, não resistiu à imersão do primeiro ciclo, apresentando, assim, uma perda de massa total. Esse solo, quando melhorado com 4,8\% de cal (Quadro 3), na energia modificada, apresentou uma perda de massa da ordem de $18 \%$ e, quando estabilizado com grits e melhorado com o mesmo teor de cal e utilizando a mesma energia de compactação (Quadro 5), apresentou uma perda de massa da ordem de $11 \%$.

Comparando os resultados dos ensaios realizados com o solo 2 melhorado com cal (Quadro 3) com aqueles obtidos no solo 2 estabilizado com o grits e melhorado com cal (Quadro 5), verificou-se que as perdas relativas ao primeiro caso foram superiores ao segundo, para uma mesma energia e teor de cal. Esse solo, quando melhorado com 4,8\% de cimento (Quadro 4), na energia modificada, teve perda de massa da ordem de $14 \%$ e, quando estabilizado com grits e melhorado com o mesmo teor de cimento (Quadro 6) e compactado na mesma energia, uma perda de massa da ordem de $9 \%$.

Comparando os resultados dos ensaios realizados com o solo 2 melhorado com cimento (Quadro 4) com aqueles obtidos para o solo 2 estabilizado com o grits e melhorado com cimento (Quadro 6), verificou-se que as perdas relativas ao primeiro caso foram, em geral, significativamente superiores ao segundo, para uma mesma energia de compactação e teor de cimento. 


\section{CONCLUSÕES}

Analisando os resultados, conclui-se que:

(a) As misturas solo-grits não apresentaram potencial de uso na construção rodoviária, com relação ao ensaio de durabilidade por molhagem e secagem.

(b) As misturas solo-cal e solo-cimento exibiram, em conformidade com vários relatos presentes na literatura, resistência a todos os 12 ciclos do ensaio de durabilidade.

(c) As amostras estabilizadas com o resíduo grits e melhoradas com cal ou cimento atenderam às exigências desse ensaio.

(d) De modo geral, observou-se que o uso do cimento e da cal potencializou os efeitos do grits nas misturas solos-aditivo.

(e) A energia de compactação, o tipo de solo, o tipo e teor de cal ou cimento empregados influenciaram significativamente os resultados do ensaio de durabilidade por molhagem e secagem.

(f) Os estabilizantes cimento e cal têm a função de ativação de reações de cimentação entre os solos e o grits.

\section{AGRADECIMENTOS}

Ao CNPq, pela concessão da bolsa de estudo ao primeiro autor; à FAPEMIG, pelo apoio financeiro; à empresa Cenibra S.A., pelo fornecimento do resíduo sólido industrial grits utilizado no estudo; e à Universidade Federal de Viçosa, através dos Departamentos de Engenharia Florestal e Civil, por ter possibilitado a execução deste trabalho.

\section{REFERÊNCIAS BIBLIOGRÁFICAS}

DEPARTAMENTO NACIONAL DE ESTRADAS DE RODAGEM-DNER-ME 129/94 : Solos: compactação utilizando amostras não trabalhadas. Método de ensaio. Rio de Janeiro: 1994. 7 p.

\section{DEPARTAMENTO NACIONALDE ESTRADAS} DE RODAGEM - DNER-ME 203: Solocimento: determinação da durabilidade através da perda de massa por molhagem e secagem: Método de ensaio. Rio de Janeiro: 1994b. 4 p.
FERNANDES, D. C. M. Viabilidade do uso de alcatrão de madeira de eucalipto na estabilização de solos residuais para fins rodoviários. 2000. 124 f. Tese (Doutorado em Engenharia Florestal) Universidade Federal de Viçosa, Viçosa, MG, 2000.

LIMA, D. C.; ROHM, S. A.; BARBOSA, P. S. A. A estabilização dos solos III:

Misturas solo-cal para fins rodoviários. Viçosa, MG: Universidade Federal de Viçosa, 1993. 32 p.

PEREIRA, R. S. Viabilidade técnica do emprego de resíduos da indústria de celulose para construção de estradas florestais. 2005. $356 \mathrm{f}$. Tese (Doutorado em Ciências Florestais) - Universidade Federal de Viçosa, Viçosa, MG, 2005.

SANT'ANA, A. P. Caracterização tecnológica de misturas solo-escória de alto-forno granulada moída para fins rodoviários. 2003. 74 f. Dissertação (Mestrado em Geotecnia) - Universidade Federal de Viçosa, Viçosa, MG, 2003.

SANT'ANNA, G. L. et al. Módulo de resiliência de um solo arenoso e de suas misturas com alcatrão fracionado e cal. Revista Árvore, n. 4, v. 27, p. 527-534, 2003.

TRINDADE, T.P. et al. Estudo da durabilidade de misturas solo-RBI-grade 81 com vistas à aplicação em estradas florestais e camadas de pavimentos convencionais. Revista Árvore, v. 29, n. 4, p. 591-600, 2005.

TRINDADE, T.P. et al. Influência do tipo de cura (selada e exposta) e da imersão em água na resistência mecânica de misturas solo-RBI grade 81 com vistas a aplicações em estradas florestais. Revista Árvore, v. 29, n. 4, p. 601-606, 2005a.

Estabilização química do subleito de estradas: Influência do tempo decorrido entre a mistura e a compactação na resistência mecânica de misturas solo-RBI grade 81 . Revista Árvore, v. 29, n. 3, p. 413-418, 2005 b. 